\title{
Pancreatic Acinar Cells Employ miRNAs as Mediators of Intercellular Communication to Participate in the Regulation of Pancreatitis-Associated Macrophage Activation
}

\author{
Yong Zhao, ${ }^{1}$ Hao Wang, ${ }^{1}$ Ming Lu, ${ }^{2}$ Xin Qiao, ${ }^{2}$ Bei Sun, ${ }^{1}$ Weihui Zhang, ${ }^{1}$ and Dongbo Xue ${ }^{1}$ \\ ${ }^{1}$ Department of General Surgery, The First Affiliated Hospital of Harbin Medical University, Harbin, Heilongjiang 150001, China \\ ${ }^{2}$ Department of Surgery, David Geffen School of Medicine, University of California, Los Angeles, Los Angeles, CA 90064, USA
}

Correspondence should be addressed to Dongbo Xue; xue9971@sina.com

Received 18 April 2016; Accepted 22 June 2016

Academic Editor: Elena Butoi

Copyright (C) 2016 Yong Zhao et al. This is an open access article distributed under the Creative Commons Attribution License, which permits unrestricted use, distribution, and reproduction in any medium, provided the original work is properly cited.

\begin{abstract}
Macrophage activation plays an important role in the inflammatory response in acute pancreatitis. In the present study, the activation of AR42J pancreatic acinar cells was induced by taurolithocholate treatment. The results showed that the culture medium from the activated AR42J cells significantly enhanced NF $\mathrm{B}$ activation in the macrophages compared to that without taurolithocholate treatment. Additionally, the precipitates obtained from ultracentrifugation of the culture media that were rich in exosomes were markedly more potent in activating macrophages compared with the supernatant fraction lacking exosomes. The results indicated that the mediators carried by the exosomes played important roles in macrophage activation. Exosomal miRNAs were extracted and examined using microarrays. A total of 115 differentially expressed miRNAs were identified, and 30 showed upregulated expression, while 85 displayed downregulated expression. Target genes of the differentially expressed miRNAs were predicted using TargetScan, MiRanda, and PicTar software programs. The putative target genes were subjected to KEGG functional analysis. The functions of the target genes were primarily enriched in MAPK pathways. Specifically, the target genes regulated macrophage activation through the TRAF6-TAB2-TAK1-NIK/IKK-NFאB pathway. As the mediators of signal transduction, miRNAs and their predicted target mRNAs regulate every step in the MAPK pathway.
\end{abstract}

\section{Introduction}

Acute pancreatitis refers to a systemic inflammatory response that progresses froma local lesion (pancreas) in the peritoneal cavity. Macrophages play an important role in the inflammatory response. Macrophages produce various cytokines and inflammatory mediators, such as interleukin- (IL-) $1 \beta$, IL6 , IL-8, and tumour necrosis factor-alpha (TNF- $\alpha$ ), which cause damage tolocal tissues and distant organs. Inhibiting the activation of pancreatitis-associated macrophages not only attenuates the pathological damage to the pancreas itself but also reduces the occurrence of systemic inflammatory response syndrome and multiple organ failure to a certain extent [1].

When elucidating the mechanisms underlying the activation of pancreatitis-associated macrophages, the essential role of intercellular communication cannot be ignored [2].
Cell-cell interactions depend on signal transduction between the cells, especially intercellular communication. The precisely divided cellular functions are closely linked through intercellular communication, allowing the coordination of the overall vital activities and the synchronization of activities such as differentiation, growth, metabolism, and movement. Therefore, intercellular communication plays an important role in the physiological and pathological processes of living organisms. Chemical signal-mediated indirect cell-cell interaction constitutes the primary form of intercellular communication [3]. Cells secrete chemical signals, such as proteins, small molecules, and other organic compounds, into the extracellular environment. The chemical signals are transported to and act on recipient cells to regulate their functions.

Previous studies proposed that pancreatic enzymes released by the damaged pancreatic tissue (i.e., trypsin, 
elastase, carboxypeptidase A, and lipase) were the mediators of intercellular communication and thus were responsible for macrophage activation in acute pancreatitis [4, 5]. Some studies found that certain lipids extracted from ascites affected macrophage activation [6]. Other studies reported that a large number of necrotic pancreatic tissues and intestinal bacteria produced lipopolysaccharides (LPS) during acute pancreatitis episodes. LPS bind specifically to the corresponding surface receptor proteins on macrophages and promote macrophage activation. Recently, the role of microRNAs (miRNAs) as mediators of intercellular communication has become a new research hotspot. miRNAs are a group of endogenous noncoding single-stranded small RNA molecules (approximately 22 nucleotides in length) with a stem-loop structure. miRNAs are widely present in eukaryotes and inhibit the expression of their target genes at the posttranscriptional level by inducing the degradation of mRNAs or suppressing the translation of mRNAs. Recently, studies have shown that a large number of miRNAs exist outside of the cells. Extracellular miRNAs are capable of mediating intercellular communication and regulating various physiological and pathological processes [7]. One of the mechanisms that allows the existence of extracellular miRNAs involves wrapping the miRNAs in exosomes to evade degradation [8,9]. Recently, numerous studies have shown that histiocytes and tumour cells selectively pack certain miRNAs into exosomes, which are transported to recipient cells via the circulatory system to regulate their gene expression [10].

In the present study, exosomal miRNAs obtained from activated AR42J pancreatic acinar cells were examined using microarrays. Additionally, the mechanisms that enabled the miRNAs to act as mediators of intercellular communication and activate macrophages were explored using bioinformatics methods. The objective of the present study was to provide a valuable reference for the intervention and regulation of macrophage activation during acute pancreatitis and for the prevention and treatment of acute pancreatitis.

\section{Materials and Methods}

2.1. Cell Culture. Rat pancreatic acinar cells (AR42J, China Centre for Type Culture Collection (CCTCC), Wuhan, China) and rat alveolar macrophages (CRL-2192 NR8383, American Type Culture Collection (ATCC), USA) were cultured in Dulbecco's modified Eagle's medium (DMEM) containing $10 \%$ foetal bovine serum (FBS), $100 \mathrm{U} / \mathrm{mL}$ of penicillin, and $100 \mu \mathrm{g} / \mathrm{mL}$ of streptomycin at $37^{\circ} \mathrm{C}$ in a $5 \%$ $\mathrm{CO}_{2}$ incubator.

The AR42J cells were divided into two groups: the control group and the taurolithocholate (TLC) treated group. The control group was left untreated, whereas the TLC treated group was incubated with $200 \mu \mathrm{M}$ TLC for $40 \mathrm{~min}$. Subsequently, the TLC-containing culture medium was discarded and replaced with fresh medium. The culture media were collected after $2 \mathrm{~h}$ of incubation. A portion of the collected media was used to extract exosomal RNAs, and the other portion was subjected to ultracentrifugation to isolate various components. The exosomal RNAs were examined using a miRNA microarray. The isolated medium components were added individually to macrophage culture medium at a $1: 1$ ratio to determine the effects of the individual components on $\mathrm{NF} \kappa \mathrm{B}$ activation in macrophages.

2.2. Cell Viability Assay and Intracellular Trypsinogen Activation of AR42J Cells. Cultured cells in 96-well plate were incubated with $1 \mathrm{mg} / \mathrm{mL}$ MTT containing medium for $3 \mathrm{~h}$ at $37^{\circ} \mathrm{C}$, and the cells were lysed with lysis buffer containing $50 \%$ of dimethyl formamide and $20 \%$ SDS. The absorbance of the dissolved MTT-derived formazan was measured at $570 \mathrm{~nm}$ using microtitre plate reader (Biotek, Vermont Winooski, USA $)$. Percentage cell viability $=(\mathrm{OD}$ of the experiment samples/OD of the control $) \times 100$.

$10^{5}$ cells $/ \mathrm{mL}$ AR42J cells were cultured for $20 \mathrm{~min}$ in HBS-EDTA ( $5 \mathrm{mM}$ HEPES, $0.15 \mathrm{M} \mathrm{NaCl}$, and $2 \mathrm{mM}$ EDTA; $\mathrm{pH}$ 7.35) with $5 \mathrm{mM}$ rhodamine 110, bis-(CBZ-L-isoleucyl-Lprolyl-L-arginine amide) dihydrochloride (BZiPAR; Molecular Probes, Invitrogen, USA). The trypsin activity was investigated by laser confocal microscopy (LSM 510 Meta, Zeiss, Germany). The experiment was repeated 3 times.

2.3. Examination of NFאB Activity in Macrophages Using an Electrophoretic Mobility Shift Assay (EMSA). Media harvested from AR42J cell cultures were centrifuged at $500 \times \mathrm{g}$ for $5 \mathrm{~min}$ to remove whole cells. The macrophages were divided into 4 groups and treated as follows: Group A: complete medium collected from the control group was added to the macrophage culture at a 1:1 ratio; Group B: complete medium collected from the TLC treated group was added to the macrophage culture at a 1:1 ratio; Group C: medium harvested from the TLC treated group was centrifuged at $15,000 \times \mathrm{g}$ at $4^{\circ} \mathrm{C}$ for $1 \mathrm{~h}$, and the supernatant was added to the macrophage culture at a 1:1 ratio; and Group D: the precipitates that were rich in exosomes were resuspended in DMEM and added to the macrophage culture at a 1:1 ratio.

The macrophages were harvested after $48 \mathrm{~h}$ of cultivation. The NF $\kappa$ B activity in the macrophages was examined using EMSA. Briefly, nuclear proteins were extracted using a Nuclear Extraction Kit (Thermo Fisher Scientific, 78833, USA) in accordance with the manufacturer's instructions and quantified using the bicinchoninic acid (BCA) assay (Beyotime, China). Subsequently, the samples ( $5 \mu \mathrm{g}$ of protein/well) were prepared according to the EMSA kit instruction manual (Thermo Fisher Scientific, 20148, USA). A 6\% TBE gel was prepared, preelectrophoresed at $100 \mathrm{~V}$ for $1 \mathrm{~h}$, and then overlaid with fresh buffer. The samples were loaded into the wells of the gel $(20 \mu \mathrm{L} /$ well $)$ and electrophoresed at $100 \mathrm{~V}$ until the bromophenol blue dye migrated approximately $2 / 3$ of the length of the gel. Then, the samples were electroblotted onto a nylon membrane ( $0.45 \mu \mathrm{m}$ pore size, Millipore, USA) with a $380 \mathrm{~mA}$ constant current for $30 \mathrm{~min}$ and cross-linked for $15 \mathrm{~min}$ at $254 \mathrm{~nm}$ using an ultraviolet cross-linker. The membrane was blocked for $15 \mathrm{~min}$. After blocking, the membrane was completely immersed in streptavidin-horseradish peroxidase (HRP) solution (1:300 dilution, Thermo Fisher Scientific, 21130, USA) and incubated at room temperature 
for $15 \mathrm{~min}$ with gentle shaking. The membrane was washed 5 times ( $5 \mathrm{~min}$ per wash) and equilibrated for $5 \mathrm{~min}$ in Substrate Equilibration Buffer. The enhanced chemiluminescence (ECL) reagent was added to the membrane and allowed to react for $2 \mathrm{~min}$. Then, the membrane was exposed to an autoradiographic film. The film was developed and fixed. The experiment was repeated 3 times.

\subsection{Extraction of Exosomal RNAs from the Culture Media of} Rat Pancreatic Acinar Cells. Exosomal RNAs were extracted using a Norgen Exosome RNA Isolation Kit (Norgen Biotek, 42800, Canada) in accordance with the manufacturer's instructions. In $50 \mathrm{~mL}$ tubes, $0.2 \mathrm{~mL}$ of PS Solution A and $1.8 \mathrm{~mL}$ of PS Solution B were added to every $1 \mathrm{~mL}$ of the medium sample after the addition of $\beta$-mercaptoethanol. The mixture was incubated at $60^{\circ} \mathrm{C}$ for $10 \mathrm{~min}$. Subsequently, $3 \mathrm{~mL}$ of $100 \%$ ethanol was added to each tube. After centrifugation at $1,000 \mathrm{rpm}$ for $30 \mathrm{~s}$, the resulting supernatants were carefully decanted. The slurry pellets were mixed thoroughly with $0.3 \mathrm{~mL}$ of PS Solution C and incubated at $60^{\circ} \mathrm{C}$ for $10 \mathrm{~min}$. After incubation, $0.3 \mathrm{~mL}$ of $100 \%$ ethanol was added to the mixture. $650 \mu \mathrm{L}$ of the mixture was loaded onto the Mini Filter Spin column and centrifuged at 14,000 rpm for $1 \mathrm{~min}$. The flow-through in the collection tube was discarded, and the spin column was reassembled with its collection tube. After the addition of $400 \mu \mathrm{L}$ of Wash Solution, the column was centrifuged at 14,000 rpm for $1 \mathrm{~min}$. The washing step was repeated 2 more times. The empty column was centrifuged for an additional $3 \mathrm{~min}$ at 14,000 rpm to completely remove any residual Wash Solution. The collection tube was discarded and the spin column was transferred to a fresh $1.7 \mathrm{~mL}$ Elution tube. After the addition of $100 \mu \mathrm{L}$ of Elution solution, the column was centrifuged at 2,000 rpm for $2 \mathrm{~min}$, followed by centrifugation at $14,000 \mathrm{rpm}$ for $3 \mathrm{~min}$.

2.5. $\mu$ Paraflo $^{\mathrm{TM}}$ MicroRNA Microarray Assay. Microarray assay was performed using a service provider (LC Sciences, USA). The assay started from $6 \mu \mathrm{g}$ total RNA sample was $3^{\prime}$ extended with a poly $(\mathrm{A})$ tail using poly $(\mathrm{A})$ polymerase. An oligonucleotide tag was then ligated to the poly(A) tail for later fluorescent dye staining. Hybridization was performed overnight on a $\mu$ Paraflo microfluidic chip using a microcirculation pump (Atactic Technologies, USA) [11, 12]. On the microfluidic chip, each detection probe consisted of a chemically modified nucleotide coding segment complementary to target microRNA (from miRBase, http://www.mirbase.org/) or other RNAs (control or customer defined sequences) and a spacer segment of polyethylene glycol to extend the coding segment away from the substrate. The detection probes were made by in situ synthesis using PGR (photogenerated reagent) chemistry. The hybridization melting temperatures were balanced by chemical modifications of the detection probes. Hybridization used $100 \mathrm{~L}$ 6xSSPE buffer $(0.90 \mathrm{M}$ $\mathrm{NaCl}, 60 \mathrm{mM} \mathrm{Na}_{2} \mathrm{HPO}_{4}$, and $6 \mathrm{mM}$ EDTA, pH 6.8) containing $25 \%$ formamide at $34^{\circ} \mathrm{C}$. After RNA hybridization, tagconjugating $\mathrm{Cy} 3$ dye was circulated through the microfluidic chip for dye staining. Fluorescence images were collected using a laser scanner (GenePix 4000B, Molecular Device,
USA) and digitized using Array-Pro image analysis software (Media Cybernetics). Data were analyzed by first subtracting the background and then normalizing the signals using a LOWESS filter (Locally-Weighted Regression) [13].

2.6. Prediction of the Differentially Expressed miRNA Target Genes. The target genes of the significantly differentially expressed miRNAs were predicted using TargetScan (http://www.targetscan.org/), MiRanda (http://www .microrna.org/microrna/home.do), and PicTar (http://pictar .mdc-berlin.de/) software programs.

The putative target genes predicted by the 3 software programs were screened separately using the scoring criteria of the corresponding software. In the TargetScan algorithm, putative target genes with a context score percentile less than 50 were excluded. In the MiRanda algorithm, putative target genes with a Max-Energy value greater than -10 were discarded. In PicTar, putative target genes with a ddG score higher than -5 were removed. The final target genes of the differentially expressed miRNAs were established by identifying the intersection of the target genes predicted by the 3 software programs.

2.7. Annotation and Enrichment Analysis of the Functions and Signalling Pathways Mediated by the Differentially Expressed miRNA Target Genes. KEGG (Kyoto Encyclopaedia of Genes and Genomes) is the primary public pathwayrelated database. Pathway enrichment analysis employs the KEGG pathway as the basic unit. Using a hypergeometric test against a whole genome background, pathway enrichment analysis identifies significantly enriched pathways associated with differentially expressed genes. $P$ values were calculated based on the following formula:

$$
P=1-\sum_{i=0}^{m-1} \frac{\left(\begin{array}{c}
M \\
i
\end{array}\right)\left(\begin{array}{c}
N-M \\
n-i
\end{array}\right)}{\left(\begin{array}{c}
N \\
n
\end{array}\right)},
$$

where $N$ represents the number of genes with pathway annotation, $n$ is the number of differentially expressed genes in $N, M$ represents the number of all genes annotated to a specific pathway, and $m$ is the number of differentially expressed genes in $M$. The threshold $P$ value was set to 0.05 . A KEGG pathway was considered significantly enriched in the differentially expressed genes if the calculated $P$ value was equal to or less than 0.05 .

A diagram depicting the miRNA target mRNA regulatory network was constructed using Cytoscape (V2.8.3). Thumbnail images of the relevant KEGG pathways were obtained from the KEGG website (http://www.kegg.jp/kegg/ pathway.html). The differentially expressed miRNAs and their target mRNAs were indicated.

2.8. Real-Time Reverse Transcription Polymerase Chain Reaction (RT-PCR) for Verification of Expression Levels of Some miRNAs and Their Target mRNAs. Total RNA was extracted from each group of cells according to the instruction manual of the RNA extraction kit (Qiagen, Hilden, Germany) and reverse transcribed into complementary DNA 


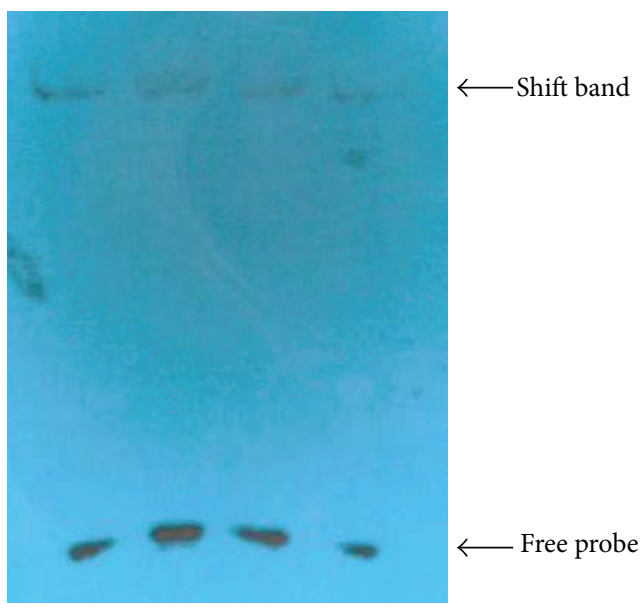

Group A Group B Group C Group D

(a)

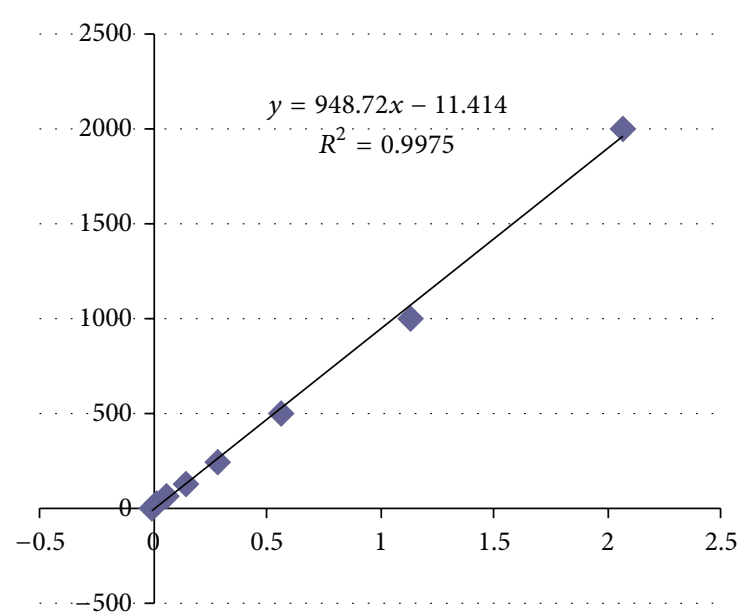

(b)

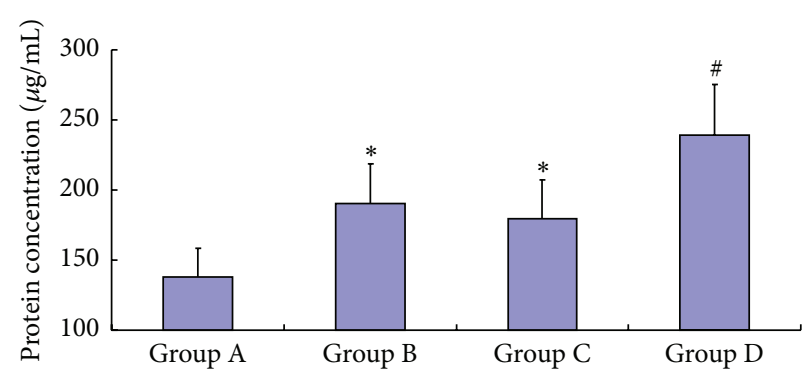

(c)

FIgURE 1: The examination of NFKB activation in macrophages. (a) Scanned EMSA gel images. (b) Standard curves. (c) Statistical graph of the EMSA results. * indicates statistically significant differences compared with Group A $(P \leq 0.05)$. \# indicates statistically significant differences compared with groups $\mathrm{B}$ and $\mathrm{C}(P \leq 0.05)$.

(cDNA) according to the manufacturer's instructions of HiFi-MMLVcDNA reverse transcription kit (CWbio. Co. Ltd., Cat\#CW0744, Beijing, China). The cDNAs were then subjected to fluorescence-based quantitative PCR using primers (Bio-Serve Co. Ltd., Shanghai, China) specific for the target mRNAs and miRNAs. The primer sequences are summarized in Table S1 in Supplementary Material available online at http://dx.doi.org/10.1155/2016/6340457. Fluorescence-based quantification was achieved using the ABI Prism 7500 Real-Time PCR system (Applied Biosystems, Foster City, CA, USA). All data were subjected to relative quantitative analysis using the $2^{-\Delta \Delta \mathrm{Ct}}$ method. Expression levels of mRNA from TLC treated AR42J cells were expressed as a multiple or fraction of the control group, which is considered arbitrarily as 1 . The experiment was repeated 3 times.

\section{Results}

3.1. The Examination of NFKB Activation in Macrophages after the Addition of Various Conditioned Media. The retarded bands representing the cross-linked DNA-protein complexes were detected on the scanned images of the EMSA gel (Figure 1(a)). The EMSA results were analyzed (Figure 1(c)).
The NF $\kappa$ B activity was significantly increased in Group B $(190.18 \pm 28.42 \mu \mathrm{g} / \mathrm{mL})$ and Group C $(179.75 \pm 27.63 \mu \mathrm{g} / \mathrm{mL})$ compared to the control group $(137.93 \pm 20.78 \mu \mathrm{g} / \mathrm{mL})(P \leq$ 0.05). Additionally, the macrophages in Group D exhibited a significantly higher level of $\mathrm{NF} \kappa \mathrm{B}$ activation (239.27 \pm $35.94 \mu \mathrm{g} / \mathrm{mL})$ compared with Group B and Group C $(P \leq$ $0.05)$.

3.2. Microarray Analysis of the Exosomal miRNAs Isolated from the Rat Pancreatic Acinar Cell Culture Media. In the present study, the TLC treated AR42J cells appeared as brighter green fluorescence than the control cells which proved that significant elevated intracellular trypsinogen activation. The quality of the extracted exosomal RNAs was assessed by real-time polymerase chain reaction (PCR) analysis of the indicators has-miR-16 and has-miR-192. Based on the range of the threshold values $(\mathrm{Ct})$ of the indicators reported in the literature, we determined that the extracted exosomal RNAs met the quality standards. Following hybridization, the microarray was scanned using a scanner. The data were extracted, LOWESS filtered and normalized, and then subjected to differential expression analysis. The quality control (QC) parameters were as follows: in the TLC treated group, the coefficient of variation $(\mathrm{CV})=6.28$ 

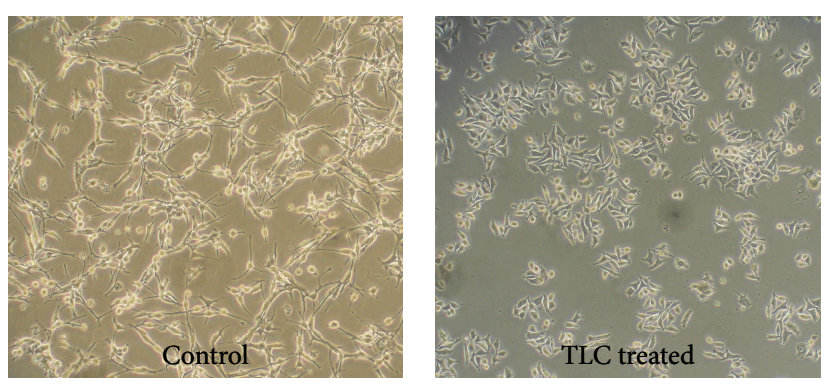

(a)
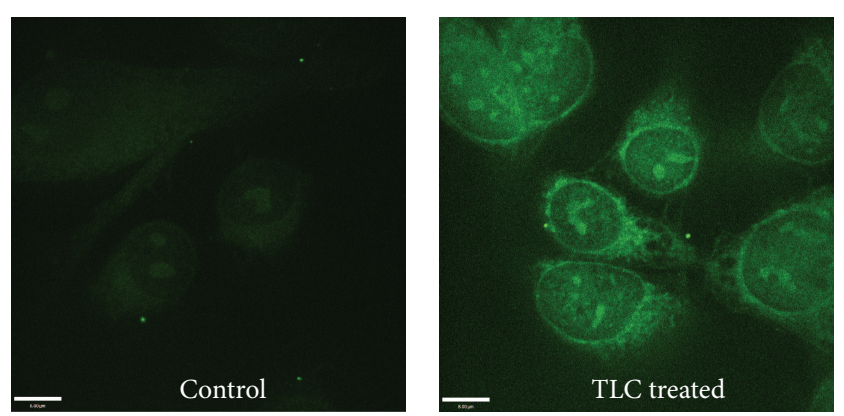

(c)

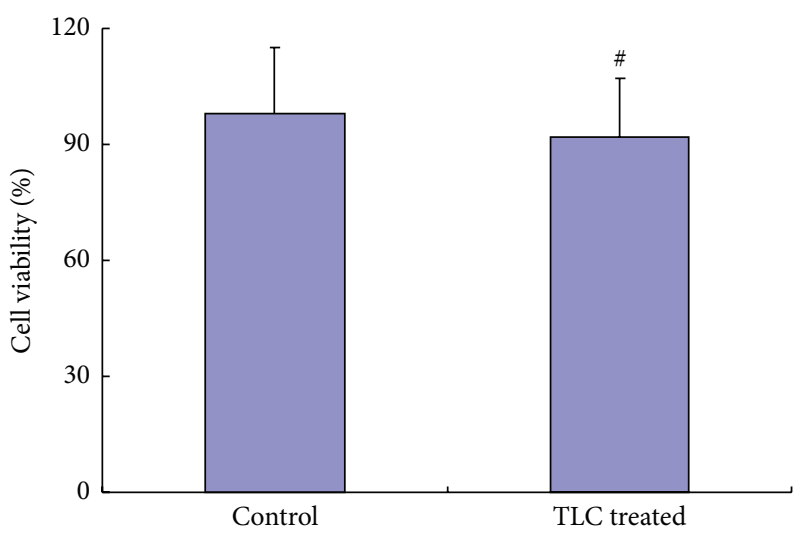

(b)
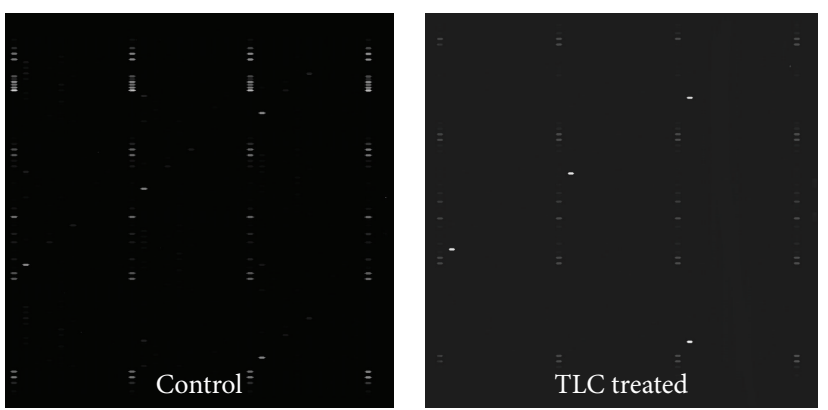

(d)
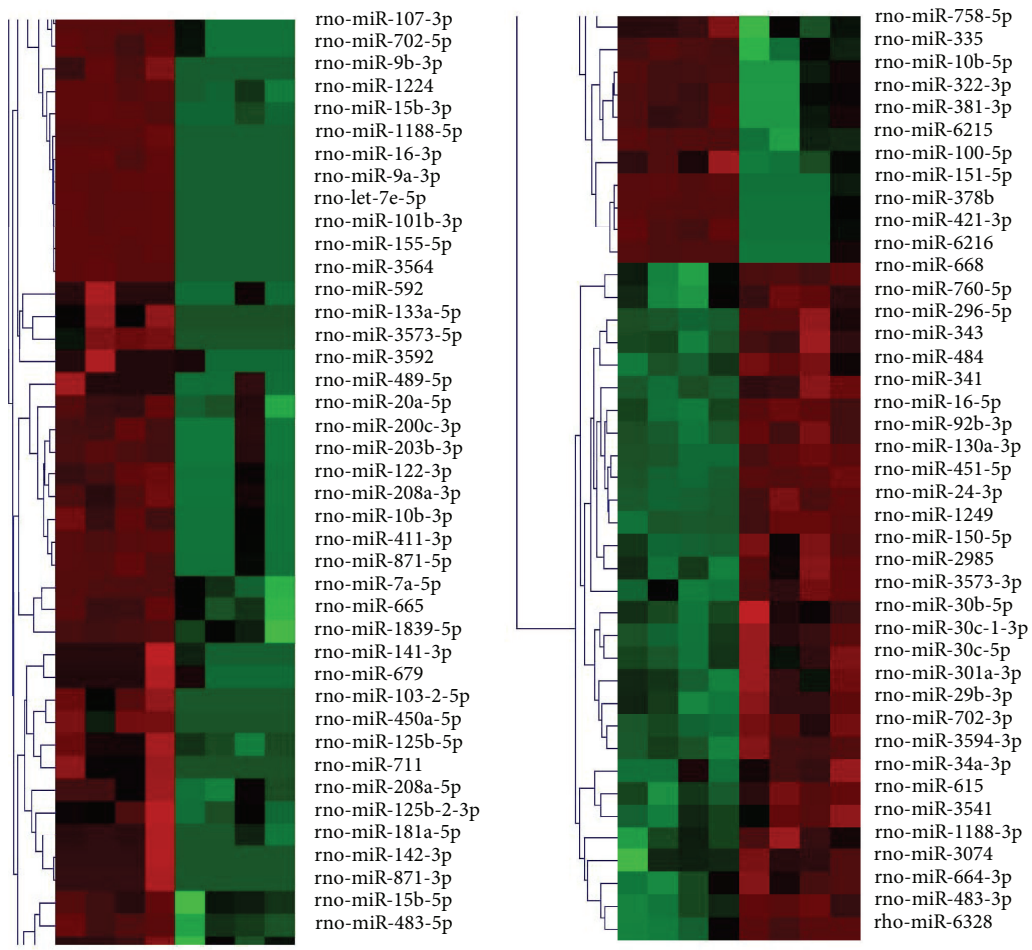

(e)

FIGURE 2: The microarray analysis of the exosomal miRNAs isolated from the culture medium of rat pancreatic acinar cells. (a) Microscopic images of cultured rat pancreatic acinar cells-AR42J cells. (b) MTT assay for detection of cell viability of AR42J cells; there is no significant difference between the two groups, ${ }^{*} P>0.05$. (c) Laser confocal microscopic images of AR42J cells labelled by BZiPAR for assessing intracellular trypsinogen activation. (d) Microarray hybridization profiles of exosomal miRNAs isolated from the culture medium of AR42J cells. (e) Cluster analysis diagram. Green denotes miRNAs expressed at low levels in the corresponding samples, whereas red denotes the miRNAs expressed at high levels in the corresponding samples. 


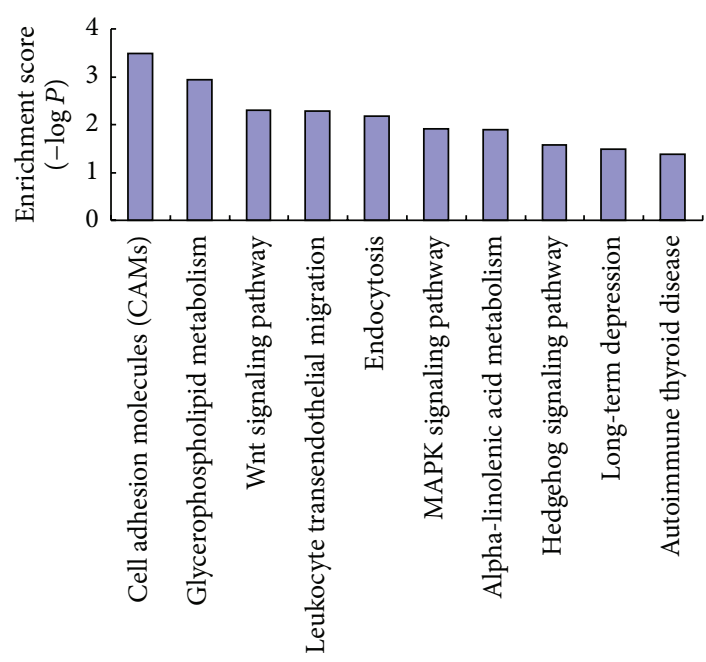

FIGURE 3: KEGG pathway analysis of genes that were regulated by differentially expressed miRNA. The enrichment score of each pathway was computed (enrichment score $=-\log P$ value).

and the QC standard was $\leq 15 \%$, and in the control group, the $\mathrm{CV}=7.68$ and the QC standard was $\leq 15 \%$. CV was defined as the ratio of the standard deviation (SD) to the mean and was expressed as a percentage. The CV was calculated using the follow formula: $\mathrm{CV}=\mathrm{SD} /$ Mean $\times 100 \%$. In the miRNA microarray analysis (LC Sciences), the stability of the microarray and the technique were evaluated by calculating the CV of the spot intensities of the repeat probes. The QC criterion recommended by LC Sciences was a CV value less than $15 \%$.

In the present study, 115 differentially expressed miRNAs were identified using the miRNA microarray. Among the differentially expressed miRNAs, 30 were upregulated and 85 were downregulated. The results of the cluster analysis are shown in Figure 2(c). The miRNA clusters are shown in the left panel of Figure 2(c). miRNAs with similar expression profiles were clustered together (bracketed together). The scale bar placed above the miRNA clusters represented the range of the $Z$ value. The formula used to calculate the $Z$ value was provided below the clusters. The $Z$ value was calculated using the following formula: $Z_{\text {sample- } i}=\left[\left(\log 2\left(\right.\right.\right.$ Signal $\left.\left._{\text {sample- } i}\right)\right)-$ Mean $(\log 2($ Signal $)$ of all samples)]/Standard deviation(log 2(Signal) of all samples)].

3.3. KEGG Pathway Enrichment Analysis of the Target Genes of the Differentially Expressed miRNAs. As shown in Figure 3, 10 KEGG pathways enriched with the functions of the differentially expressed miRNAs were identified using a $P$ value threshold of 0.05 . The pathways included cell adhesion molecules (CAMs), glycerophospholipid metabolism, the Wnt signalling pathway, leukocyte transendothelial migration, endocytosis, the MAPK signalling pathway, alphalinolenic acid metabolism, the Hedgehog signalling pathway, long-term depression, and autoimmune thyroid disease. After conducting a comprehensive literature search, we found that the MAPK signalling pathway (ranked 6 among the KEGG pathways) was closely related to the activation of macrophages and NF $\mathrm{B}$. Therefore, the MAPK signalling pathway was the focus of our subsequent analyses.

3.4. The Regulatory Effect of the miRNAs and Their Target $m R N A s$ in the MAPK Pathway on NFKB Activation. Using Cytoscape software, we constructed a network diagram depicting the mutual regulation between the miRNAs and mRNAs in the KEGG pathways (Figure 4). We found that 71 differentially expressed miRNAs were responsible for the regulation of 129 mRNAs. The miRNAs and mRNAs constituted 338 interacting pairs.

Thumbnail images of the MAPK pathways provided by the KEGG website were employed to display the KEGG pathways and the distribution of the significantly differentially expressed genes in the KEGG pathways and to discover and provide useful information (Figure 5). The predicted target genes of the differentially expressed miRNAs were denoted with red boxes. As shown in Figure 5, the target genes of the differentially expressed miRNAs regulated NF $\mathrm{B}$ activation through the TNF receptor-associated factor 6 (TRAF6) (TGF-beta activated kinase 1/MAP3K7 binding protein 1 (TAB1) or TGF-beta activated kinase 1/MAP3K7 binding protein 2 (TAB2)) transforming growth factor beta activated kinase 1 (TAK1) $(\mathrm{NF} \kappa \mathrm{B}$ inducing kinase (NIK) or I $\kappa$ B kinase $(\mathrm{IKK})) \mathrm{NF} \kappa \mathrm{B}$ pathway. Additionally, specific differentially expressed miRNAs participated in the regulation of these target genes, thereby affecting NFאB activation. The regulatory pairs were as follows: $\mathrm{miR}-128-3 \mathrm{p}$ and $\mathrm{miR}-15 \mathrm{~b}-5 \mathrm{p}$ regulate TRAF6; miR-615, miR-6328, and miR-668 regulate TAB1; miR-3594-3p, miR-423-5p, miR-24-3p, and miR-483$5 p$ regulate TAB2; miR-679 and miR-674-5p regulate TAK1; miR-423-5p, miR-665, and miR-151-5p regulate NIK; miR3573-5p, miR-761, miR-665, and miR-3541 regulate IKK; and miR-674-5p regulates $\mathrm{NF} \kappa \mathrm{B}$.

3.5. Expression of miRNAs and Their Target mRNA Verified by Real-Time RT-PCR. The results of real-time RT-PCR verified that the expression level of miR-668, miR-3594-3p, miR-243p, miR-483-5p, miR-3541, and TRAF6, TAB2, TAK1, NIK, and IKK was upregulated in TLC treated group $(P<0.05)$, while the expression level of miR-128-3p, miR-15b-5p, miR679, miR-423-5p, miR-665, miR-151-5p, miR-761, was miR615 downregulated $(P<0.05)$; see Figure 6. The real-time RTPCR results showed that the expression of miR-674-5p, miR615, miR-6328, and miR-3573-5p was not in accordance with the results of chip detection. And TAB1 showed no significant elevated $(P>0.05)$.

\section{Discussion}

Currently, the mechanisms underlying the acute pancreatitisinduced systemic inflammatory response syndrome are commonly thought to include the overactivation of leukocytes and the release of excessive amounts of cytokines. Monocytes/macrophages are thought to play a crucial role in 


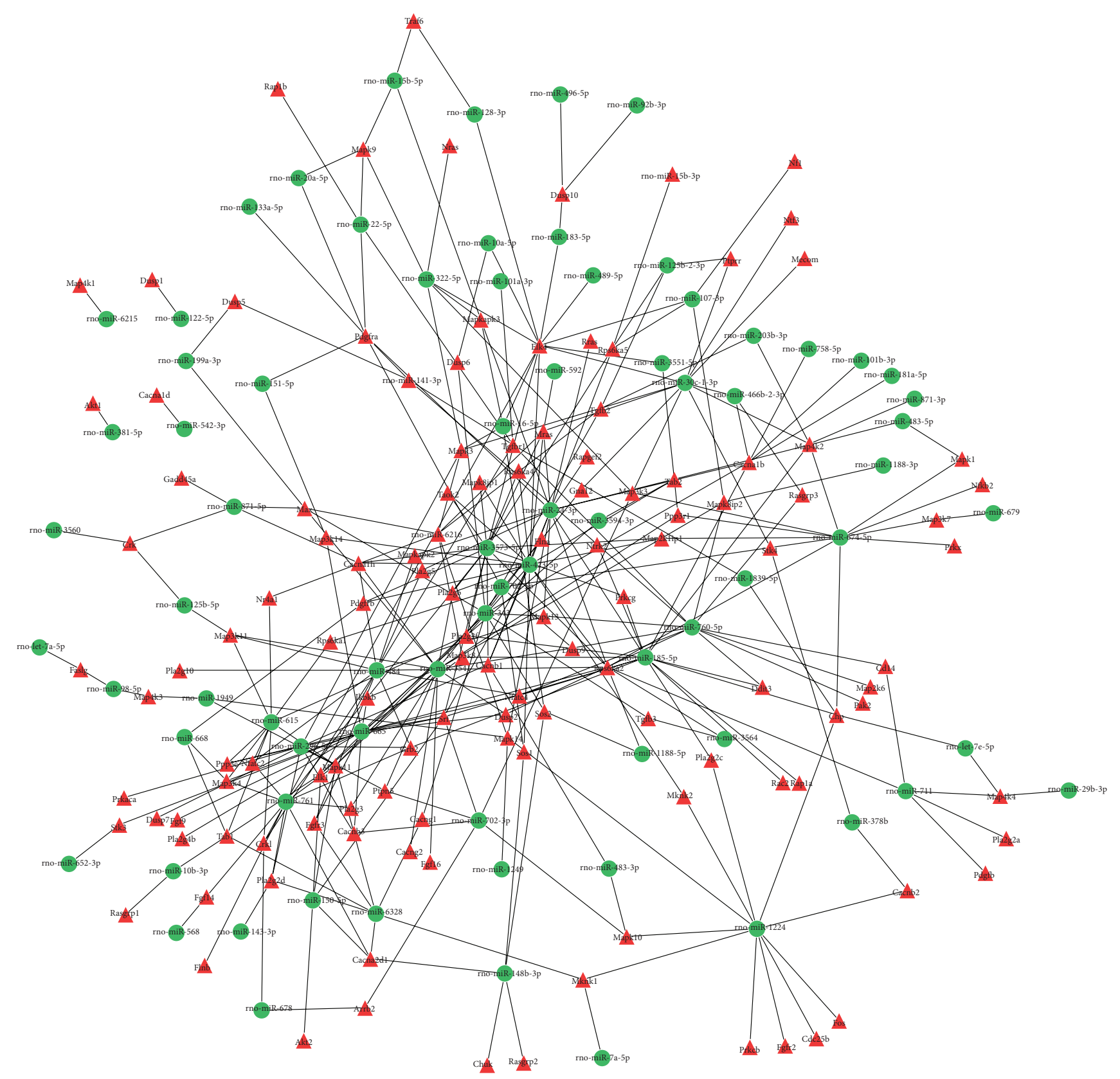

FiguRE 4: Interaction network of differentially expressed miRNAs and their regulated target genes. Green ellipse shape nodes refer to differentially expressed miRNA, and red triangle shape nodes refer to their regulated target genes.

the above process [14]. Acute pancreatitis begins with the activation of trypsinogen. The damaged pancreatic cells release a variety of proinflammatory mediators that first stimulate pancreatic macrophages, followed by peritoneal macrophages and then macrophages in the liver, lungs, and gastrointestinal tract. The overactivated monocytes/macrophages secrete more proinflammatory cytokines, which enter the blood circulation and contribute to the development of the systemic inflammatory response syndrome. Therefore, an exploration of the activation mechanisms of pancreatitisassociated macrophages may achieve a valuable breakthrough in the clarification of the pathogenesis of acute pancreatitis and the systemic inflammatory response related to acute pancreatitis [15]. Inhibiting macrophage activation has been shown to attenuate the pathological damage to the pancreas and improve prognoses to a certain extent. Shifrin et al. [16] established a mouse model of viral infection-induced acute pancreatitis and used dichloromethylene diphosphonate to deplete macrophages. The results showed that macrophage depletion increased the mouse survival rate. The study conducted by Souza et al. [17] found that the TNF- $\alpha$, IL6 , and IL-10 serum levels were reduced in mice with acute pancreatitis after clearance of macrophages by peritoneal lavage. Gloor et al. $[18,19]$ reported that selective clearance 


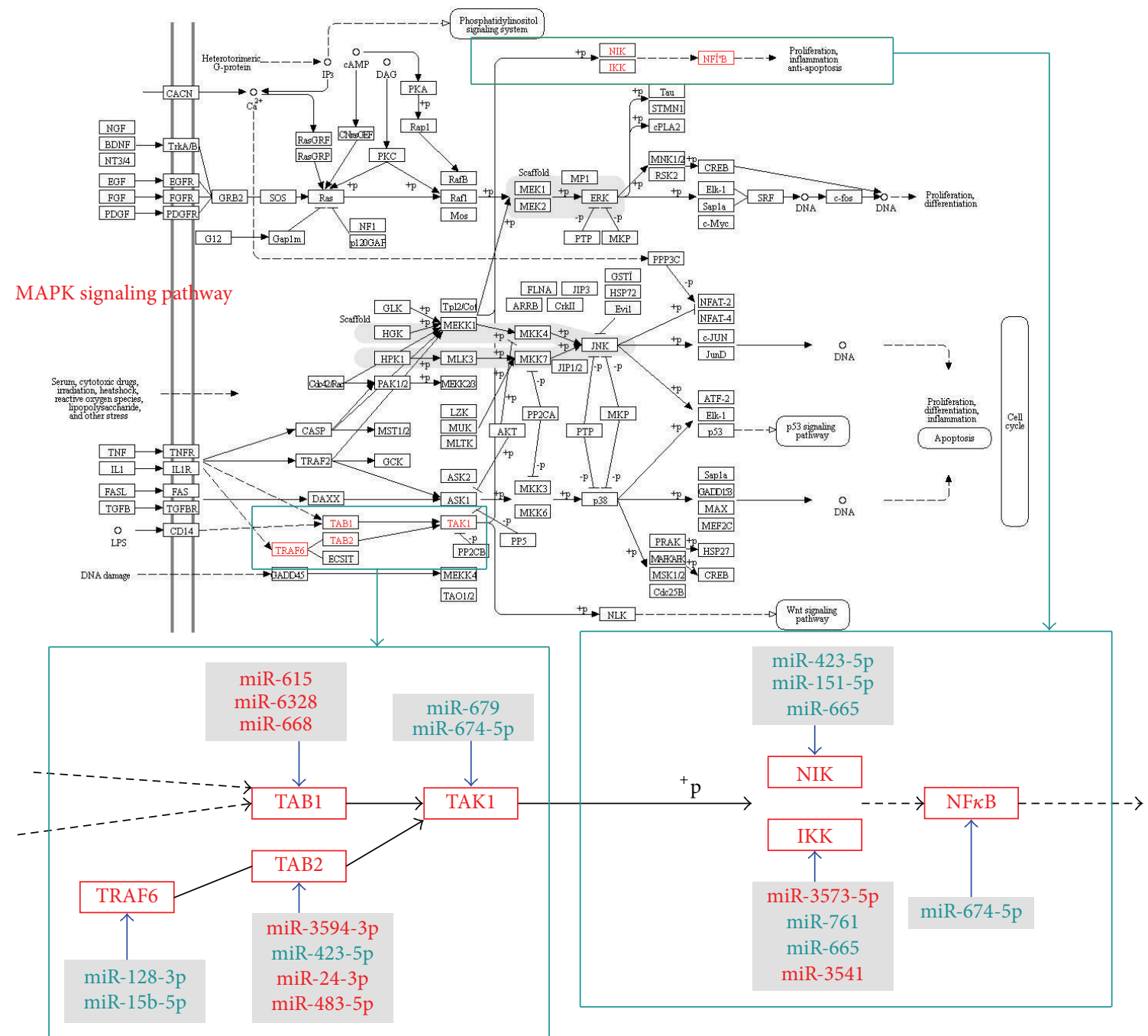

Figure 5: Thumbnail image of MAPK signalling pathway. The genes labelled red were genes that were regulated by differentially expressed miRNA. The miRNAs labelled red were the upregulated miRNAs, and the miRNAs labelled green were the downregulated miRNAs.

of macrophages in different organs led to improvements in both organ and systemic lesions. Thus, cell-level therapies that target macrophages have become a hotspot and the regulation of macrophage functions has become a new research direction in the treatment of acute pancreatitis.

$\mathrm{NF} \kappa \mathrm{B}$ plays an important role in the activation of acute pancreatitis-related macrophages [20]. The $\mathrm{NF} \kappa \mathrm{B}$ and $\mathrm{p} 38$ MAPK signalling pathways were shown to be activated in circulating monocytes in a taurine-induced acute pancreatitis model [21]. Another study showed that NFאB induced the activation of virulizin, which further promoted the production of TNF- $\alpha$ by peritoneal macrophages [22]. The study conducted by Ma et al. [23] found that the administration of resveratrol decreased the expression of $\mathrm{NF} \kappa \mathrm{B}$ and inducible nitric oxide synthase (iNOS) in in vitro cultured peritoneal macrophages and reduced the TNF- $\alpha$, IL-1, and nitric oxide (NO) levels in the culture medium and serum. Gutierrez et al. [6] found that coculture of macrophages with the ascites from model mice with acute pancreatitis resulted in macrophage activation. However, the addition of the NF $\kappa \mathrm{B}$ inhibitor pyrrolidine dithiocarbamate (PDTC) to the culture medium terminated macrophage activation. In the present study, the activation of pancreatic acinar cells was induced by TLC treatment. When the activated pancreatic acinar cellconditioned culture medium was added to the macrophage culture, the results showed that the culture medium from the activated pancreatic acinar cells significantly enhanced the level of $\mathrm{NF} \kappa \mathrm{B}$ activation in the macrophages compared to culture medium from cells without TLC treatment. Thus, the activated pancreatic acinar cells promoted the activation of macrophages through the activity of certain mediators. To identify these mediators, culture media were subjected to ultracentrifugation, and we observed the effects of the supernatant fractions lacking exosomes and of the precipitates, which were rich in exosomes. The results showed that the precipitates were markedly more potent in activating macrophages than the supernatant fractions, indicating that the exosomes and the mediators carried by the exosomes played an important role in macrophage activation. Extracellular RNAs carried by exosomes and other vesicles are capable 


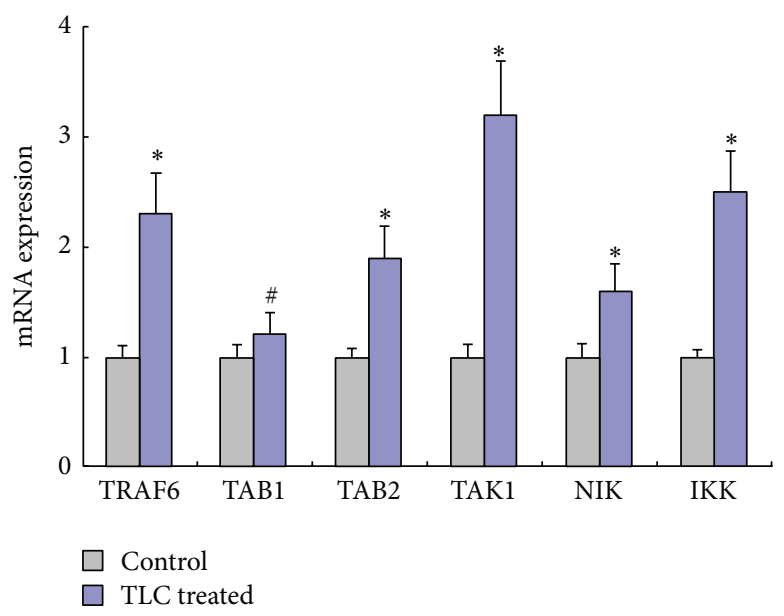

(a)

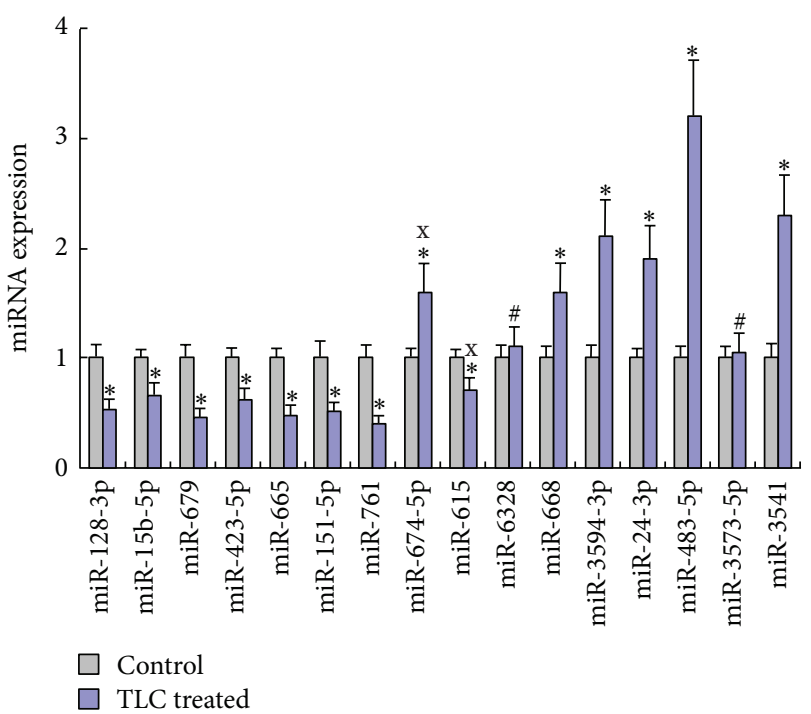

(b)

Figure 6: Expression levels of mRNA or miRNA detected by real-time RT-PCR. ${ }^{*}$ Compared to control group, $P<0.05$. ${ }^{\#}$ Compared to control group, $P>0.05 .{ }^{\mathrm{x}}$ The expression level was incompatible between the chip and real-time RT-PCR detection.

of regulating intracellular RNA signals in recipient cells. Therefore, extracellular RNA has become a novel therapeutic target.

To explore these mediators of signal transduction, the extracted exosomal RNAs were examined using a miRNA microarray. The results showed significant differences in the miRNA expression profiles between the exosomes secreted by the TLC treated pancreatic acinar cells and the exosomes secreted by the untreated pancreatic acinar cells. A total of 115 differentially expressed miRNAs were identified, among which 30 showed upregulated expression and 85 displayed downregulated expression. The differentially expressed miRNAs carried by the exosomes were integrated into the recipient cells with the exosomes and affected recipient cell functions. At present, studies have demonstrated that miRNAs exert a regulatory effect on macrophage activation. Taganov et al. [24] stimulated macrophages with LPS and found that the expression of certain miRNAs was increased. Zhang et al. [25] discovered that 109 miRNAs were differentially expressed between murine bone marrow-derived $\mathrm{M} 1$ and M2 macrophages, suggesting that miRNAs were involved in the regulation of macrophage polarization. To elaborate the functions of the miRNAs that acted as mediators of signal transduction, we predicted the target genes of the miRNAs and annotated the functions of the target genes in the present study. Additionally, we performed KEGG pathway enrichment analysis. Among the significantly enriched pathways, the MAPK signalling pathways were the most closely related to the activation of macrophages and $\mathrm{NF} \kappa \mathrm{B}$.

There is a large amount of evidence that MAPKs are involved in the activation of a number of proinflammatory nuclear transcription factors, including $\mathrm{NF} \kappa \mathrm{B}$, and that the MAPK signalling pathways interact with the NFKB signalling pathway [26-29]. We mapped the miRNAs and miRNAregulated target mRNAs to the MAPK signalling pathways and found that the differentially expressed miRNAs primarily acted on the TRAF6-TAB2-TAK1-NIK/IKK-NF $\kappa$ B pathway. In the above pathways that regulate $\mathrm{NF} \kappa \mathrm{B}$ activation, multiple differentially expressed miRNAs target and regulate every step of the pathway, thereby ultimately affecting $N F \kappa B$ and macrophage activation.

In the MAPK pathways, binding of LPS to toll-like receptor 4 (TLR4) enables transmission of activating signals downstream via the toll/IL-1 receptor (TIR) domain, resulting in the sequential activation of interleukin-1 receptorassociated kinase (IRAK), TRAF6, TAK1, IKK, and other key molecules. These key molecules activate $\mathrm{NF} \kappa \mathrm{B}$, thereby enhancing the transcription and expression of the proinflammatory cytokines IL-1, IL- 6 , and TNF- $\alpha$ and activating monocytes/macrophages [13]. The results of the present study revealed that the differentially expressed miRNAs carried by exosomes were capable of modulating various steps in the MAPK pathways.

TRAF6 is a member of the tumour necrosis factor receptor- (TNFR-) associated factor family and a key mediator that is capable of simultaneously transducing signals from the TNFR superfamily and the IL-1R/TLR superfamily [3032]. As an important adapter molecule, TRAF6 regulates the expression of a series of proinflammatory factors through NF $\kappa$ B, including TNF- $\alpha$, IL-2, IL-6, IL-8, and IL-12 [33, 34]. The results of the present study revealed that TRAF6 was a target of exosome-carried miR-128-3p and miR-15b-5p.

TAB1/2 are adaptor proteins for TRAF6. TRAF6 effectively activates its downstream protein TAK1 with the assistance of TAB1/2. The present study found that, among the differentially expressed miRNAs, miR-423-5p regulated TAB2.

TAK1 is a member of the MAP kinase kinase kinase (MKKK) family. TAK1, which is a special activating factor for TAB1, and TRAF6 jointly activate the downstream kinases 
NIK and IKK [35]. TAK1 has been demonstrated to play an important role in the TLR4-dependent LPS signalling system, which activates $\mathrm{NF} \kappa \mathrm{B}$ [36]. Additionally, TAK1 exerts a regulatory effect on $\mathrm{MKKK}$ during TLR/IL-1 receptorinitiated p38MAPK activation [37, 38]. The present study found that TAK1 was the target of downregulated miR-679.

Membrane receptors transmit signals to NIK, which then selectively stimulates the IKK complex composed of IKK $\alpha$ and IKK $\beta$ and catalyses the phosphorylation of inhibitor of kappa B $(\mathrm{I} \kappa \mathrm{B})$. As a result, the key protein/immediateearly nuclear transcription factor capable of promoting cell growth $(\mathrm{NF} \kappa \mathrm{B})$ is released in an active functional state to promote cellular DNA transcription and enhance the expression of related genes $[39,40]$. The present study found that downregulated miR-423-5p, miR-665, and miR-151-5p targeted NIK, whereas downregulated miR-761 and miR-665 exerted their regulatory effect by targeting IKK.

\section{Conclusions}

In summary, activated pancreatic acinar cells regulate macrophage activation and $\mathrm{NF} \kappa \mathrm{B}$ activation by secreting exosomes carrying differentially expressed miRNAs. During the process of $\mathrm{NF} \kappa \mathrm{B}$ activation in macrophages, the differentially expressed miRNAs act as mediators to regulate various steps of the TRAF6-TAB2-TAK1- NIK/IKK-NF $\kappa B$ pathway (one of the MAPK signalling pathways). Therefore, the present study provides novel ideas for future studies of the regulation of pancreatitis-associated macrophage activation and the alleviation of the progression of acute pancreatitis.

\section{Competing Interests}

The authors declare that there is no conflict of interests regarding the publication of this paper.

\section{Acknowledgments}

This study was supported by the Heilongjiang Traditional Chinese Medicine Scientific Research Project of China (ZHY12-W035) and National Natural Science Foundation of China (81570579).

\section{References}

[1] Q. Ni, W. Zhang, K. Sun, C. Yin, J. An, and D. Shang, "effects of emodin on peritoneal macrophage intercellular adhesion molecule-3 in a rat model of severe acute pancreatitis/systemic inflammatory response syndrome," Biomedical Reports, vol. 2, no. 1, pp. 63-68, 2014.

[2] Y. Fujita, Y. Yoshioka, and T. Ochiya, "Extracellular vesicle transfer of cancer pathogenic components," Cancer Science, vol. 107, no. 4, pp. 385-390, 2016.

[3] H. Thomas, M. Jäger, K. Mauel, S. Brandau, S. Lask, and S. B. Flohé, "Interaction with mesenchymal stem cells provokes natural killer cells for enhanced IL-12/IL-18-induced interferongamma secretion," Mediators of Inflammation, vol. 2014, Article ID 143463, 11 pages, 2014.
[4] A. H. Lundberg, J. W. Eubanks III, J. Henry et al., "Trypsin stimulates production of cytokines from peritoneal macrophages in vitro and in vivo," Pancreas, vol. 21, no. 1, pp. 41-51, 2000.

[5] C. Jaffray, C. Mendez, W. Denham, G. Carter, and J. Norman, "Specific pancreatic enzymes activate macrophages to produce tumor necrosis factor-alpha: role of nuclear factor kappa B and inhibitory kappa B proteins," Journal of Gastrointestinal Surgery, vol. 4, no. 4, pp. 370-378, 2000.

[6] P. T. Gutierrez, E. Folch-Puy, O. Bulbena, and D. Closa, "Oxidised lipids present in ascitic fluid interfere with the regulation of the macrophages during acute pancreatitis, promoting an exacerbation of the inflammatory response," Gut, vol. 57, no. 5, pp. 642-648, 2008.

[7] E.-A. Ye and J. J. Steinle, "miR-146a attenuates inflammatory pathways mediated by TLR $4 / \mathrm{NF}-\kappa \mathrm{B}$ and TNF $\alpha$ to protect primary human retinal microvascular endothelial cells grown in high glucose," Mediators of Inflammation, vol. 2016, Article ID 3958453, 9 pages, 2016.

[8] C. Di Pietro, "Exosome-mediated communication in the ovarian follicle," Journal of Assisted Reproduction and Genetics, vol. 33, no. 3, pp. 303-311, 2016.

[9] C. Burbano, M. Rojas, G. Vásquez, and D. Castaño, "Microparticles that form immune complexes as modulatory structures in autoimmune responses," Mediators of Inflammation, vol. 2015, Article ID 267590, 15 pages, 2015.

[10] J. R. Chevillet, Q. Kang, I. K. Ruf et al., "Quantitative and stoichiometric analysis of the microRNA content of exosomes," Proceedings of the National Academy of Sciences of the United States of America, vol. 111, no. 41, pp. 14888-14893, 2014.

[11] X. Gao, E. Gulari, and X. Zhou, "In situ synthesis of oligonucleotide microarrays," Biopolymers, vol. 73, no. 5, pp. 579-596, 2004.

[12] Q. Zhu, A. Hong, N. Sheng et al., "microParaflo biochip for nucleic acid and protein analysis," Methods in Molecular Biology, vol. 382, pp. 287-312, 2007.

[13] B. M. Bolstad, R. A. Irizarry, M. Åstrand, and T. P. Speed, "A comparison of normalization methods for high density oligonucleotide array data based on variance and bias," Bioinformatics, vol. 19, no. 2, pp. 185-193, 2003.

[14] S. Gea-Sorlí, R. Guillamat, A. Serrano-Mollar, and D. Closa, "Activation of lung macrophage subpopulations in experimental acute pancreatitis," The Journal of Pathology, vol. 223, no. 3, pp. 417-424, 2011.

[15] X.-W. Xu, X.-M. Yang, Y.-H. Bai et al., “Treatment with ginkgo biloba extract protects rats against acute pancreatitis-associated lung injury by modulating alveolar macrophage," Przeglad Gastroenterologiczny, vol. 9, no. 1, pp. 43-48, 2014.

[16] A. L. Shifrin, N. Chirmule, Y. Zhang, and S. E. Raper, "Macrophage ablation attenuates adenoviral vector-induced pancreatitis," Surgery, vol. 137, no. 5, pp. 545-551, 2005.

[17] L. J. Souza, A. M. Coelho, S. N. Sampietre, J. O. Martins, J. E. Cunha, and M. C. MacHado, "Anti-inflammatory effects of peritoneal lavage in acute pancreatitis," Pancreas, vol. 39, no. 8, pp. 1180-1184, 2010.

[18] B. Gloor, T. A. Blinman, D. A. Rigberg et al., "Kupffer cell blockade reduces hepatic and systemic cytokine levels and lung injury in hemorrhagic pancreatitis in rats," Pancreas, vol. 21, no. 4, pp. 414-420, 2000.

[19] B. Gloor, K. E. Todd, J. S. Lane, M. P. N. Lewis, and H. A. Reber, "Hepatic Kupffer cell blockade reduces mortality of acute hemorrhagic pancreatitis in mice," Journal of Gastrointestinal Surgery, vol. 2, no. 5, pp. 430-435, 1998. 
[20] Y. Zhang, Y. Wang, M. Lu et al., "Modular analysis of bioinformatics demonstrates a critical role for NF- $\kappa$ B in macrophage activation," Inflammation, vol. 37, no. 4, pp. 1240-1253, 2014.

[21] Z. Chen, Y. Chen, L. Pan et al., "Dachengqi decoction attenuates inflammatory response via inhibiting HMGB1 mediated NF- $\kappa \mathrm{B}$ and P38 MAPK signaling pathways in severe acute pancreatitis," Cellular Physiology and Biochemistry, vol. 37, no. 4, pp. 13791389, 2015.

[22] H. Li, M. Y. Cao, Y. Lee et al., "Virulizin ${ }^{\circledR}$, a novel immunotherapy agent, stimulates TNF $\alpha$ expression in monocytes/macrophages in vitro and in vivo," International Immunopharmacology, vol. 7, no. 10, pp. 1350-1359, 2007.

[23] Z.-H. Ma, Q.-Y. Ma, L.-C. Wang, H.-C. Sha, S.-L. Wu, and M. Zhang, "Effect of resveratrol on NF- $\kappa$ B activity in rat peritoneal macrophages," The American Journal of Chinese Medicine, vol. 34, no. 4, pp. 623-630, 2006.

[24] K. D. Taganov, M. P. Boldin, K.-J. Chang, and D. Baltimore, "NF$\kappa \mathrm{B}$-dependent induction of microRNA miR-146, an inhibitor targeted to signaling proteins of innate immune responses," Proceedings of the National Academy of Sciences of the United States of America, vol. 103, no. 33, pp. 12481-12486, 2006.

[25] Y. Zhang, M. Zhang, M. Zhong, Q. Suo, and K. Lv, "Expression profiles of miRNAs in polarized macrophages," International Journal of Molecular Medicine, vol. 31, no. 4, pp. 797-802, 2013.

[26] D. E. Williard, E. Twait, Z. Yuan, A. B. Carter, and I. Samuel, "Nuclear factor kappa B-dependent gene transcription in cholecystokinin- and tumor necrosis factor- $\alpha$-stimulated isolated acinar cells is regulated by p38 mitogen-activated protein kinase," American Journal of Surgery, vol. 200, no. 2, pp. 283-290, 2010.

[27] T. A. Blinman, I. Gukovsky, M. Mouria et al., "Activation of pancreatic acinar cells on isolation from tissue: cytokine upregulation via p38 MAP kinase," American Journal of PhysiologyCell Physiology, vol. 279, no. 6, pp. C1993-C2003, 2000.

[28] E. Twait, D. E. Williard, and I. Samuel, "Dominant negative p38 mitogen-activated protein kinase expression inhibits NF$\kappa \mathrm{B}$ activation in AR42J cells," Pancreatology, vol. 10, no. 2-3, pp. 119-128, 2010.

[29] L. Koch, D. Frommhold, K. Buschmann, N. Kuss, J. Poeschl, and P. Ruef, "LPS- and LTA-induced expression of IL-6 and TNF- $\alpha$ in neonatal and adult blood: role of MAPKs and NF$\kappa \mathrm{B}$," Mediators of Inflammation, vol. 2014, Article ID 283126, 8 pages, 2014.

[30] J. Yan, Y. Yin, W. Zhong, C. Wang, and Z. Wang, "CD137 regulates NFATcl expression in mouse VSMCs through TRAF6/NF$\kappa$ B p65 signaling pathway," Mediators of Inflammation, vol. 2015, Article ID 639780, 10 pages, 2015.

[31] W. Zhang, T. He, Q. Wang et al., "Interleukin-1 receptorassociated kinase- 2 genetic variant rs708035 increases NF- $\kappa$ B activity through promoting TRAF6 ubiquitination," The Journal of Biological Chemistry, vol. 289, no. 18, pp. 12507-12519, 2014.

[32] X. Wang, T. Ha, J. Zou et al., "MicroRNA-125b protects against myocardial ischaemia/reperfusion injury via targeting p53mediated apoptotic signalling and TRAF6," Cardiovascular Research, vol. 102, no. 3, pp. 385-395, 2014.

[33] H. Konno, T. Yamamoto, K. Yamazaki et al., "TRAF6 establishes innate immune responses by activating NF- $\kappa \mathrm{B}$ and IRF7 upon sensing cytosolic viral RNA and DNA," PLoS ONE, vol. 4, no. 5, Article ID e5674, 2009.

[34] H. Liu, S. Tamashiro, S. Baritaki et al., "TRAF6 activation in multiple myeloma: a potential therapeutic target," Clinical
Lymphoma, Myeloma and Leukemia, vol. 12, no. 3, pp. 155-163, 2012.

[35] C. Wang, L. Deng, M. Hong, G. R. Akkaraju, J.-I. Inoue, and Z. J. Chen, "TAK1 is a ubiquitin-dependent kinase of MKK and IKK," Nature, vol. 412, no. 6844, pp. 346-351, 2001.

[36] V. T. Ha, H. S. Beak, E. Kim et al., "NF- $\kappa$ B/AP-1-targeted inhibition of macrophage-mediated inflammatory responses by depigmenting compound AP736 derived from natural 1,3diphenylpropane skeleton," Mediators of Inflammation, vol. 2014, Article ID 354843, 11 pages, 2014.

[37] M. Boutros, H. Agaisse, and N. Perrimon, "Sequential activation of signaling pathways during innate immune responses in Drosophila," Developmental Cell, vol. 3, no. 5, pp. 711-722, 2002.

[38] D. H. Kim, R. Feinbaum, G. Alloing et al., "A conserved p38 MAP kinase pathway in Caenorhabditis elegans innate immunity," Science, vol. 297, no. 5581, pp. 623-626, 2002.

[39] I. Stancovski and D. Baltimore, "NF- $\kappa$ B activation: the I $\kappa$ B kinase revealed?” Cell, vol. 91, no. 3, pp. 299-302, 1997.

[40] M. D. Sanchez-Nio, A. Benito-Martin, S. Gonalves et al., "TNF superfamily: a growing saga of kidney injury modulators," Mediators of Inflammation, vol. 2010, Article ID 182958, 11 pages, 2010. 


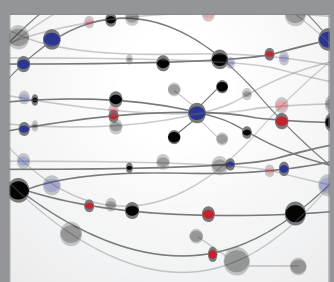

The Scientific World Journal
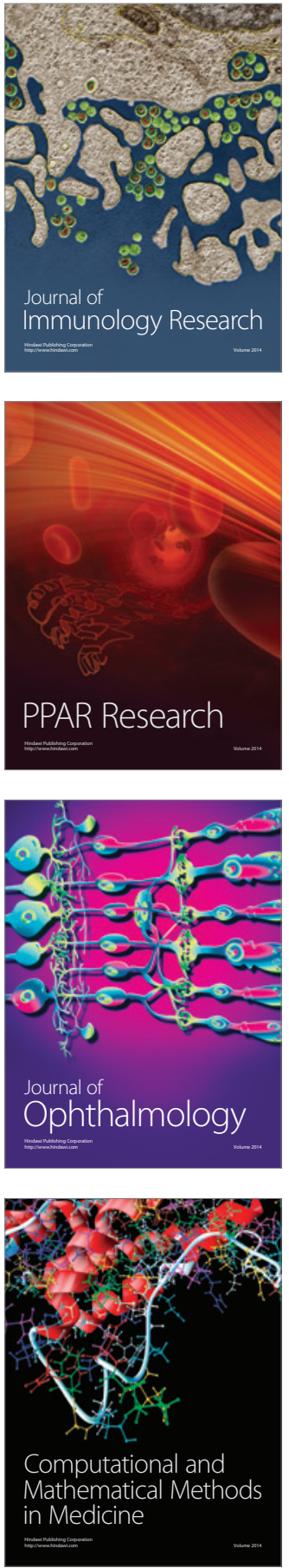

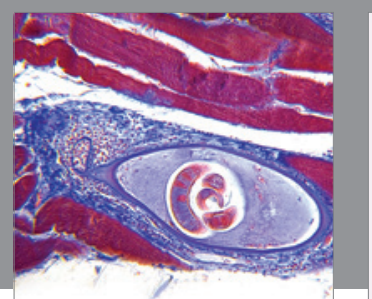

Gastroenterology Research and Practice

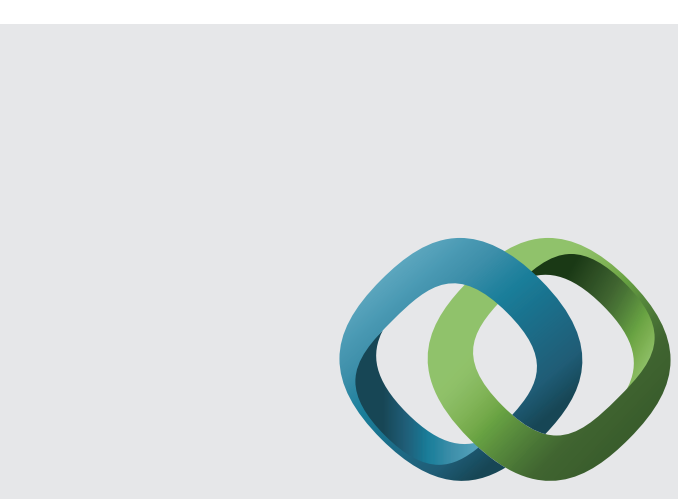

\section{Hindawi}

Submit your manuscripts at

http://www.hindawi.com
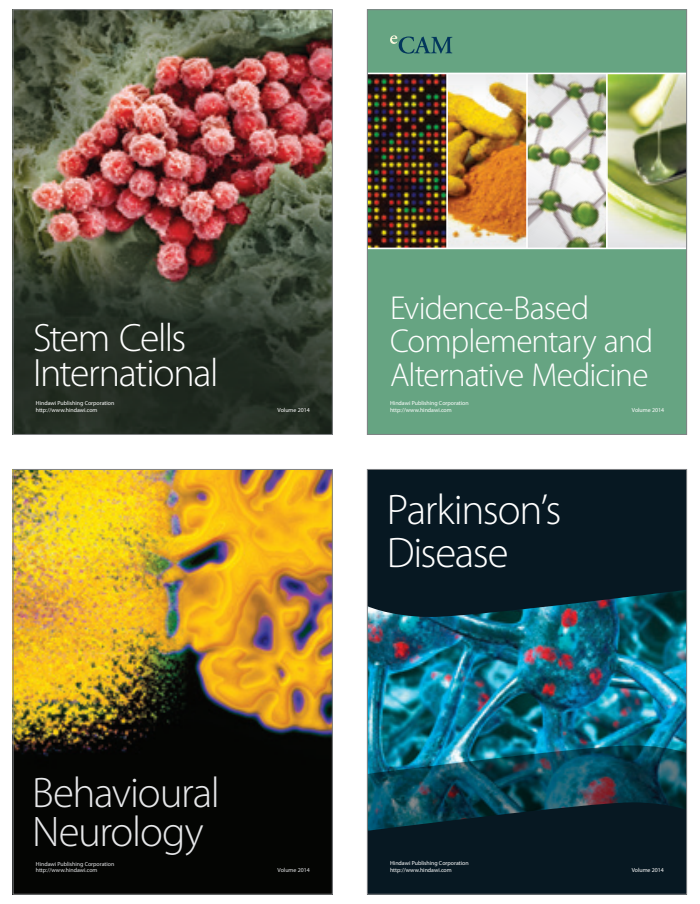
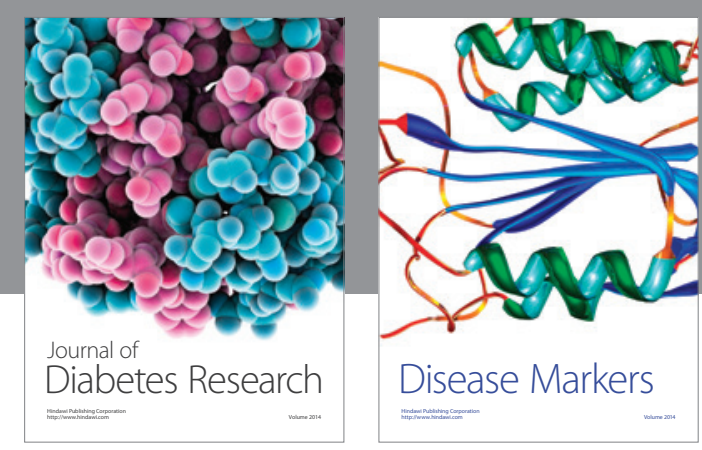

Disease Markers
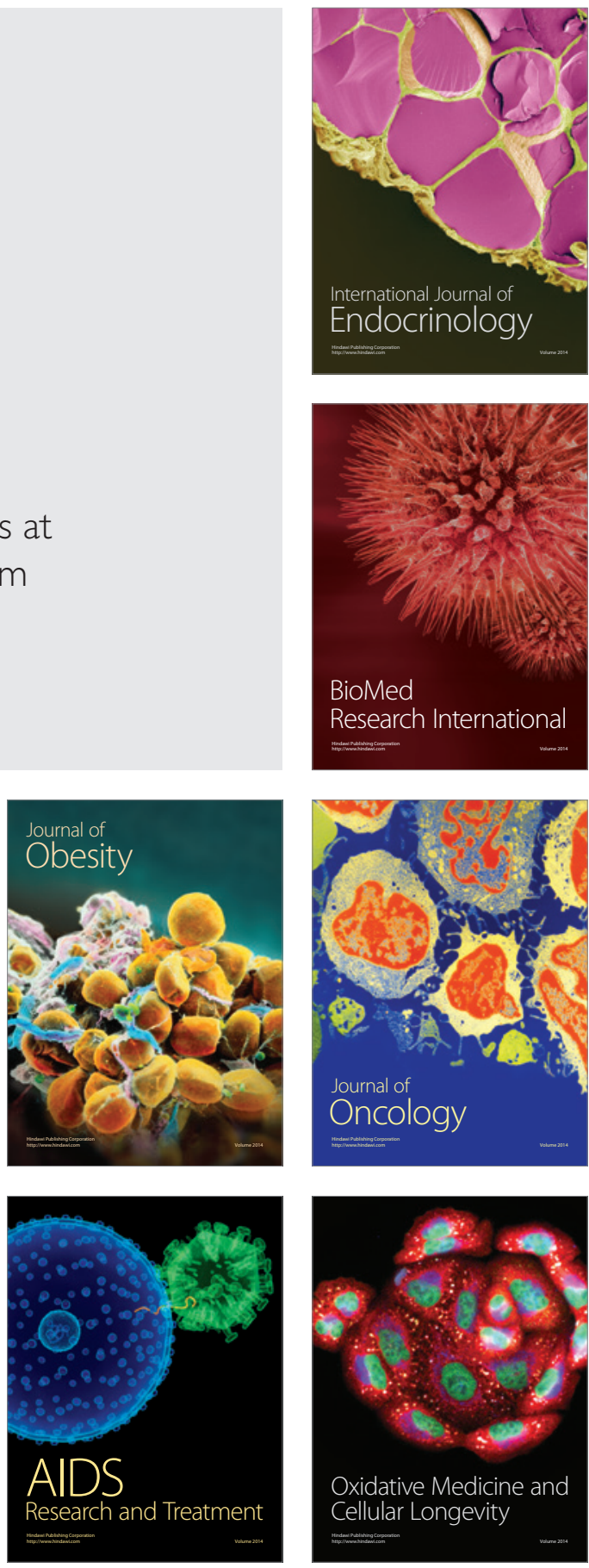